been the true explanation in all? The rapid and early developments in the successful Madras cases may be held to correspond merely with the direct corneal traumatism inflicted in these experiments-scratching and massage.

Controls appear to be needed consisting of exactly similar traumatism at an epidemic period, without the use of any epithelial emulsion from diseased eyes, but possibly with the application of emulsions, filtered and unfiltered, taken from healthy eyes.

\title{
OCULAR PLUMBISM IN CHILDREN
}

\author{
BY \\ J. LOCKHART GiBSON \\ HONORARY CONSULTING OPHTHALMOLOGIST, \\ BRISBANE HOSPITAL FOR SICK CHILDREN
}

(Summary.-The cases dealt with in this paper have no pyrexia. The mild ones are brought by their mothers because they have developed a recent internal squint. The squint is due to paralysis of one or of both external recti. Papilloedema up to six dioptres is found, due to increase of intra-cranial tension. The severe cases are more evidently cases of lead encephalopathy. Explanation is given of why soluble lead is available, and why and how it is ingested. Lead is found in the urine. No albumin is found in the urine.)

Although I have written on this subject in Australia, I have only published one paper in England, and my knowledge has increased and become more accurate since then.

The peculiar nature of the cases described has not as a rule been thoroughly recognized. They appear to have no parallel among cases of industrial lead poisoning, and nearly all writers on lead poisoning where the eyes are implicated, have had experience of industrial lead poisoning only, and of that in adults. My reason for frequent references to the cases I have seen in Queensland has been the desire of myself and of my colleagues, especially of those at the Hospital for Sick Children, to get a danger removed from our young children between the ages of two years and eight years; and also to make isolated cases in other places and other countries less likely to be undiagnosed as due to lead-to bring lead at least into the differential diagnosis of such cases in young children.

It has been difficult for those practising in other parts of Australia to recognize the special conditions under which our children live, and the special facilities they have for ingesting lead. It has proved quite impossible for many of those who have investigated industrial lead poisoning to grasp the fact that whereas industrial lead poisoning occurs owing to the inhalation of lead dust, our children are poisoned owing to the ingestion of 
powdered soluble lead carbonate. The explanation given of how this soluble lead carbonate is ingested, and the reason why such poisoning among children is less common, or absent, elsewhere than in Queensland, industrial lead investigators are unable to appreciate.

The British Medical Association, Queensland Branch, succeeded after many years in getting the Government to make it penal to apply lead paint to outside surfaces within the reach of young children. This law has been in force since 1923, though not always obeyed by master painters. It, and still more the persistent teaching of parents by those of us who grasp the importance, has resulted in many fewer cases of hand and foot drop, and of ocular plumbism.

The ocular plumbic cases, if secured early and treated promptly, will recover without any defect in sight. I am personally answerable for claiming them to be due to lead, for claiming them to be a result of increased intra-cranial tension, and for the explanation that the lead circulating in the vessels of the choroid plexus causes the increased secretion of cerebro-spinal fluid.

The frequency of wrist drop and foot drop cases, which were readily diagnosed as due to lead, caused me to diagnose the eye cases. I am sensible that it would have taken much longer to arrive at this conclusion in the eye cases had it not been for the wrist and foot drop cases. The two conditions very rarely occur together. Latterly, I have been able to explain this, and Woollard's work with dyes has supported my explanation in an interesting manner, as I will explain later.

We were able to diagnose the limb cases and the eye cases for years before I was able to discover how and where they ingested their lead.

In Queensland, houses are built on piles. The verandah floors and other floors are therefore several feet above the ground. All our dwelling houses, which are chiefly wooden, have verandahs more or less broad. They require verandah railings. These railings are of wood, and in the neighbourhood of towns they are painted. Except where other paints are insisted upon, they have been painted with white lead paint. In this semi-tropical climate, the sun soon converts this paint into a powdery substance. The powder rubs off easily on the hands. This powder our Government analyst in 1904 proved for me to be a very soluble carbonate of lead. Garden fences are painted with the same material. Such paint inside our houses or unexposed to the sun and outside atmosphere, does not powder at all appreciably. The children between the ages of two years and eight years spend a large part of their time on the verandahs, girls more than boys. They are apt to finger and to cling to the verandah rails. I soon 
found that the children in a family who become affected with lead bite their nails, and the few who do not, suck their fingers, or occasionally suck the paint. It was found that more girls were affected than boys; that more cases occurred during the summer months than in the cooler months, because the moist hands of children during the hot months carry more of the lead powder to their mouths than the dry hands of winter.

The cases of wrist drop and foot drop were first described by the staff of the Hospital for Sick Children in 1892. I was then an Honorary Physician. Since then, Dr. A. Jefferis Turner especially, and other members of the staff, have published papers. The eye cases I have recognized since 1897, when I became Honorary Ophthalmologist to the Hospital. At first they were named by me ocular neuritis due to lead, and thought to be due, like other lead cases, to peripheral neuritis. Latterly, I have regretted this name, because ocular plumbism would be more accurate.

Continued observations and treatment revealed the existence of increased intra-cranial tension in the ocular plumbic cases, and that the papilloedema and paralysis or paresis found in the external recti muscles was due to this increased intra-cranial tension. It was found that if the cases were admitted, i.e., removed from the opportunity of ingesting more lead before the increased intracranial tension had lasted for long, a prompt lumbar puncture, followed, if necessary, by a second lumbar puncture in three days, very quickly resulted in reduction of the papilloedema and of the squint. I say " resulted " because we had been able to contrast what happened after I had insisted upon lumbar puncture becoming a routine practice with what happened when I did a lumbar puncture only in cases with marked head symptoms in addition to the papilloedema and squint.

I am, of course, conscious that the ocular plumbic cases are cases of lead encephalopathy, but to give them so high sounding a name might defeat my object, which is to get practitioners elsewhere than in large cities to deal with them promptly when a doubt exists regarding the aetiolgy. The removal of the child from further possible contact with powdery lead paint, and the performance of a prompt lumbar puncture, is the essential treatment, i.e., remove the cause or further cause, and reduce the pressure, which will destroy the sight if it lasts long enough. (The amount of fluid removed on the first puncture varies from 2 drachms to 18 drachms.)

The early cases hardly appear to be ill, and would be unrecognized by their parents except for the sudden and fortunate development of a squint. The severe cases are, if undiagnosed, again fortunate in being so sick that they are confined to bed and so removed from further ingestion of lead. This limits the damage to 
vision, but as a rule results in complete or partial postpapilloedemic atrophy in one or both eyes unless a timely lumbar puncture is done.

The Government analyst, after taking every precaution to exclude contamination of specimens and reagents, found lead in sufficient quantities in the urine of the children to prove the absorption of lead. What the faeces contained had not necessarily been absorbed from the intestinal canal, and was not therefore of importance.

Occasional cases similar in all respects occurred when children had been allowed access to fresh paints, either on recently painted houses or in pots of paint used by their fathers in the house. The following case is one in point :-

October, 1913.-H. H., male, aged 5 years 8 months; sent to me by Dr. Coen, of Lismore, New South Wales. The illness began a month ago with vomiting without relation to food and lasting ever since except for three days intermission; frontal and temporal headache; internal squint noticed for two weeks, and double vision.

Examination : Child very pale. Paralysis of each external rectus and a very marked internal squint. Eating nothing to speak of until the last two days. Temperature normal. Intense papilloedema (choked disc) in each eye. Discs raised six dioptres; veins very distended; retina surrounding each disc swollen; no head retraction; said to see well-can see my fingers at six yards. Nails are all bitten.

The house has no verandah railings, but the garden is surrounded by railings painted with white lead five or six years ago, and now very powdery. His father does some painting and mixes white lead paints in the house. He has been mixing some lately, specially for a month before the boy became ill. Since the boy has been sick, he has been too ill to go near either his father's paints or the garden railings. He had been decidedly better for the last two days, his mother told me. Family history excellent. I gained the impression that he was beginning to show benefit from being too ill to play with his father's paints, and therefore to continue the ingestion of lead.

Ocular plumbism was the provisional diagnosis. An immediate lumbar puncture was done. The cerebro-spinal fluid was under pressure, but not to the extreme degree often found in lead cases and only two drachms of fluid were withdrawn. (No doubt the extreme pressure was subsiding.) He slept well that night, and his headache disappeared and did not return. The right external rectus showed some return in power next day. In four days the external recti were acting fairly well and there was little squint. In five days there was only two dioptres of swelling in each disc. In 14 days only a trace of alternate squint persisted and the papilloedema had subsided. He had been given, of course, dilute sulphuric acid and magnesium sulphate, followed after the first week with potassium iodide. He was allowed to return to his home in the north of New South Wales.

In August, 1929, i.e., 16 years later, a broad shouldered, particularly healthy-looking young man-a typical footballercalled to tell me how grateful he and his parents had been to me. His vision was six-fifths with each eye. Each fundus was natural, and refraction emmetropic. One had to imagine that the slightly irregular edges of the discs may have been a legacy of the papilloedema. There was no sign of any ophthalmoplegia.

The ocular plumbic cases being due, as I think, to the ingestion of a considerable quantity of lead during a short time-a few weeks-would not be expected to lead to the serious sequelae which chronic lead poisoning in childhood is supposed by some of my physician colleagues to be answerable for in young adults. Dr. Nye 
has, indeed, made out a very good case for the unusual number of nephritic young people in Queensland being a result of ingestion of lead in childhood. This case and others help to confirm the aetiology of the more usual eye cases. The hand and foot drop cases are almost always a result of prolonged ingestion of small quantities of lead. The ocular cases, I believe, ingest considerable quantities over a short time. This explains what has always been a difficulty - why some children get hand and foot drop, and others only ocular plumbism. Why more massive doses over a short time cause eye symptoms may, I think, be explained by an observation of Woollard, who found that if small doses of dyes are given, no head symptoms result, because apparently the cerebral circulation is fenced against them. If, on the other hand, large doses are given, head symptoms and convulsions occur. I believe that the lead circulating in the choroid plexus causes an increased secretion of intra-cranial fluid and consequent increased intra-cranial pressure, with resulting papilloedema and paralysis or paresis of the external ocular muscles, nearly always of the external recti. I have known all the ocular muscles implicated in a severe case brought too late to prevent blindness. The squint is always recovered from.

As said before, my chief object in again writing on this subject is the hope that it may lead to isolated cases being at least provisionally recognized and treated, and blindness amongst children thereby reduced. I think also that my explanation of how and why papilloedema is caused is original and correct.

We have found that a good substitute for lead paint is zinc white. When used without admixture with lead, it lasts on exposed surfaces longer than lead. It powders less, and its powder is not poisonous. I have had only one voluntary explanation as to why master painters resist wholeheartedly the use of any paint whose basis is not lead. The senior painter in Brisbane said to me when I first began to urge zinc as a substitute: "You know, Doctor, we painters do not like this zinc craze." "Why, Mr. . . . ." I asked. "It lasts too long," came the answer. Those interested in white lead manufacturing resist for other reasons also.

\section{REFERENCES}

J. Lockhart Gibson :

"Plumbic Ocular Neuritis in Queensland Children." Australasian Med. Gaz., October 20, 1897.

"Painted Railings the Source of Lead Poisoning." Australasian Med. Gaz., April 20, 1904.

"Plumbic Ocular Neuritis." Australasian Med. Gaz., 1904.

Transactions of the Australasian Medical Congress, 1905, 7th Session. Brit. Med. Jl., November 14, 1908. 
J. Lockhart Gibson:

"Importance of Lumbar Puncture in Plumbic Ocular Neuritis." Australasian Med. Gaz., January 13, 1912.

"The Diagnosis, Prophylaxis and Treatment of Plumbic Ocular Neuritis." Med. Jl. of Australia, September 8, 1917.

"De-ionization in the Treatment of Plumbic Ocular Neuritis." Med. Jl. of Australia, April 5, 1919.

"Exhibition of Cases of Ocular Plumbism." Transactions of the Australasian Medical Congress, Brisbane, 1920.

A. Jefferis Turner : A ustralasian Med. Gaz., 1897.

W. E. Dixon and Halliburton:

"Cerebro-spinal Pressure." Jl. of Physiol., Vol. XLVII, No. 3, pp. 283 and 287.

H. H. Woollard:

"Capillary Endothelium." Med. Jl. of Australia, August 4, 1928.

D. Gifford Croll :

"Chronic Nephritis in Queensland." Med. Jl. of Australia, August 3, 1929.

L. J. Jarvis Nye:

"Chronic Nephritis in Queensland." Med. Jl. of Australia, August 3, 1929.

\section{END RESULTS IN MONOCULAR ESOTROPIA*}

BY

Luther C. Peter, M.D.

FROM THE DEPARTMENT OF OPHTHALMOLOGY, GRADUATE SCHOOL OF MEDICINE, UNIVERSity OF PENNSYLVANiA, PHILAdELPHIA, PA., U.S.A.

OpINIONS are divided as to what may be expected as end results in monocular squint. Many believe that only parallelism can be obtained in the great majority of patients, with an exceptionally good termination now and then, including equal visual acuity in the two eyes and, to all intents and purposes, single binocular vision. In fact, not many years ago a member of this Society, an unusually good operator, expressed his belief in a paper that comparatively few children recover from squint with single binocular vision. There is, however, a minority of operators, in which the speaker is included, who believe the ideal goal can be obtained in the vast majority of young squinters, if systematic measures are instituted, if the squint is treated at the proper age, and if the co-operation of the parents can be obtained.

It might be well to state just what the ideal goal embraces in order to say " the results are ideal." In my judgment, ideal results include, first, good visual acuity in the squinting eye; second, single binocular vision which will stand the proper tests;

* Read by invitation, at the Annual Meeting of the Pacific Coast Oto-Oph thalmological Society, May 29, 1931, Los Angeles, California, U.S.A. 